of warning bleeds (for example, unexplained bruising, nose bleeds, and umbilical oozing) and often occurs in babies with undiagnosed liver disease. The incidence of intracranial haemorrhage could be much reduced if the grave significance of warning bleeds was always recognised and if, in all babies still jaundiced at 2-3 weeks, underlying liver disease was considered $^{20}$ and vitamin $\mathrm{K}$ status reviewed. Finally, while we continue to debate vitamin $\mathrm{K}$ regimens we should be unanimous in promoting breast feeding.

GERALD DRAPER Director

Childhood Cancer Research Group,

University of Oxford,

Oxford OX2 6HJ

ANDREW McNINCH

Consultant paediatrician

Royal Devon and Exeter Hospital,

Exeter EX2 5DW

1 Meyer TC, Angus J. The effect of large doses of 'Synkavit' in the newborn. Arch Dis Child 1956;31:212-5.

2 Allison AC. Danger of vitamin K to newborn. Lancet 1955;i:669.
3 Laurance B. Danger of vitamin K analogues to newborn. Lancet 1955;i:819.

4 Vitamin $K$ and the newborn [editorial]. Lancet 1978;i:755-7.

5 Whitfield MF, Salfield SAW. Accidental administration of Syntometrine in adult dosage to the newborn. Arch Dis Child 1980;55:68-70.

6 Choonara IA, Park BK. Plasma concentrations after oral or intramuscular vitamin $\mathrm{K}$ in neonates. Arch Dis Child 1985;60:1203-4.

7 Ekelund H. Late haemorrhagic disease in Sweden 1987-89. Acta Paediatr Scand 1991;80:966-8.

$8 \mathrm{McNinch} \mathrm{AW}$, Tripp JH. Haemorrhagic disease of the newborn in the British Isles: two year prospective study. BMf 1991;303:1105-9.

9 Expert Committee. Vitamin K prophylaxis in infancy. London: British Paediatric Association, 1992.

10 Croucher C, Azzopardi D. Compliance with recommendations for giving vitamin K to newborn

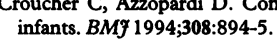

11 Von Kries R, Gobel U. Oral vitamin $K$ prophylaxis and late haemorrhagic disease of the newborn. Lancet 1994;343:352.

12 Golding J, Paterson M, Kinlen LJ. Factors associated with childhood cancer in a national cohort study. Br f Cancer 1990;62:304-8.

13 Golding J, Greenwood R, Birmingham K, Mott M. Childhood cancer, intramuscular vitamin K, and pethidine given during labour. $B M Y$ 1992;305:341-6.

14 Ekelund $\mathrm{H}$, Finnstrơm $\mathrm{O}$, Gunnarskog J, Källén $B$, Larsson $Y$. Administration of vitamin $K$ to newborn infants and childhood cancer. $B M \mathcal{F}$ 1993;307:89-91.

15 Olsen JH, Hertz $H$, Blinkenberg $K$, Verder $H$. Vitamin $K$ regimens and incidence of childhood cancer in Denmark. $B M \mathcal{F}$ 1994;308:895-6.

16 Rennie JM, Kelsall AWR. Vitamin K prophylaxis in the newborn-again. Arch Dis Child 1994;70:248-51.

17 Klebanoff MA, Read JS, Mills JL, Shiono PH. The risk of childhood cancer after neonatal exposure to vitamin K. N Engl f Med 1993;329:905-8.

18 Slattery JM. Why we need a clinical trial for vitamin K. BMY 1994;308:908-10.

19 Amédeé-Manesme O, Lambert W, Alagille D, De Leenheer AP. Pharmacokinetics and safety of a new solution of vitamin $K_{1(20)}$ in children with cholestasis. $f$ Pediatr Gastroenterol Nutr 1992;14:160-5.

20 Logan S, Stanton A. Screening for biliary atresia. Lancet 1993;342:256.

\title{
Tetrahydroaminoacridine and Alzheimer's disease
}

\author{
For the few, but we don't know which few
}

Tetrahydroaminoacridine (THA, tacrine), a cholinesterase inhibitor with several other actions that could enhance cognitive function, ${ }^{1}$ has passed the Food and Drug Administration's stringent licensing procedure for use in treating "mild to moderate" Alzheimer's disease. ${ }^{2}$

Since the first claim of its efficacy in Alzheimer's disease in a controlled trial in $1986^{3}$ further studies have been almost equally divided between those reporting benefit for some patients with Alzheimer's disease and those reporting no benefit ${ }^{4}$ (such as the study by Maltby in this issue p $879^{5}$ ). No washout period or inadequate outcome measures are apparent in most studies, and comparison between them is also complicated by the concurrent use of lecithin in some studies. The dosage of tetrahydroaminoacridine varies widely, between $20 \mathrm{mg}$ and $114 \mathrm{mg}$ a day, as does the duration of treatment, from one to 13 weeks. The studies also report high rates of adverse effects, the commonest being hepatoxicity (affecting up to $30 \%$ of patients) and cholinergic effects (especially gastrointestinal troubles), although mostly these unwanted effects were mild and reversible.

One of the commonest errors in drug trials is to include too few patients; the study then has insufficient power to prove or disprove the hypothesis. Some of the early studies of tetrahydroaminoacridine may have been flawed in this way. Most well designed trials with adequate numbers of subjects show that tetrahydroaminoacridine benefits some patients. ${ }^{6-8}$ The benefits are expressed either as improvement in the core deficits of Alzheimer's disease (both cognitive and noncognitive $)^{6-8}$ or as a reduced rate of deterioration. ${ }^{7}$ What is more, evidence exists that these benefits are not always restricted to performance on rating scales but may be of practical value to patients and carers. ${ }^{8}$ Much less clear is how long such benefits will last (follow up has been short) or which patients are likely to benefit.

Not all patients with Alzheimer's disease benefit from tetrahydroaminoacridine. Response rates in those studies showing a modest benefit range between 3\% and 50\%. Only very few patients improve greatly. ${ }^{6}$ The dose may be important: a daily dose of tetrahydroaminoacridine less than $125 \mathrm{mg}$ (100 mg of the active base) may be inadequate; a possible dose related response has been reported. ${ }^{8}$ The heterogeneity of Alzheimer's disease ${ }^{10}$ may explain why only some patients respond. Subtypes of Alzheimer's disease have been described, ${ }^{10}$ but evidence for distinct entities within the generic term Alzheimer's disease is less than satisfactory."

What is needed now is a close comparison of patients who respond to tetrahydroaminoacridine with those who do not. One group may already be identifiable-those with diffuse Lewy body disease, ${ }^{12}$ who may include patients who fulfil operational criteria for Alzheimer's disease such as those of McKhann et al..$^{13}$ Such patients, because of a profound cholinergic deficit, may respond to anticholinergic treatments. ${ }^{14}$ The postmortem finding (reported by $\mathrm{R}$ Levy at the International Psychogeriatric Association meeting in Berlin last September) that three patients in the Institute of Psychiatry's trial who had responded to tetrahydroaminoacridine had cortical Lewy bodies supports this suggestion. As well as identifying the clinical characteristics of responders and non-responders, further studies might use imaging techniques such as single photon emission computed tomography ${ }^{15}$ or brain electrical activity mapping, ${ }^{16}$ which may detect changes in brain function before rating scores do.

The ratio of risk to benefit seems to be tilting in favour of the use of tetrahydroaminoacridine for some patients with Alzheimer's disease, but much more work is needed to identify those who are likely to gain practical benefits. An application for tetrahydroaminoacridine to be licensed in Britain has been submitted. The variable response and toxicity profile suggest that, if licensed, tetrahydroaminoacridine should be given only in specialist centres with adequate facilities for investigating and monitoring patients (there is specific guidance on monitoring in the Food and Drug Administration approval ${ }^{2}$ ), which would undertake to document their patients meticulously. Collaborative evaluation by such centres should provide the numbers of subjects 
needed to answer more precisely the question that is still very open. Useful? Yes, probably; but for whom?

E JANE BYRNE

Senior lecturer

Department of Old Age Psychiatry,

Withington Hospital,

Manchester M20 8LR

TOM ARIE

Professor of health care of the elderly

Medical School,

Queen's Medical Centre,

Nottingham NG7 2UH

1 Byme EJ, Arie T. Tetrahydroaminoacridine (THA) in Alzheimer's Disease. BMf 1989;298:845-6. 2 FDC Report 1993;13 Sep:6-8.

3 Summers WK, Majouski LV, March GM, Morris JC, Kawas CH, Tachikik K, et al. Oral tetrahydroaminoacridine in long-term treatment of senile dementia, Alzheimer's type. $N$ Engl $f$ Med 1986;315:1241-5.

4 Wilcock GK, Surman DJ, Scott M, Boyle M, Mulligan K, Neubauer KA, et al. An evaluation of the efficacy and safety of tetrahydroaminoacridine (THA) without lecithin in the treatment of Alzheimer's disease. Age Ageing 1993;22:316-24.

5 Maltby N, Broe GA, Creasey H, Jorm AF, Christensen H, Brooks wS. The long term efficacy of treating mild-moderate Alzheimer's disease with tetrahydroaminoacridine and lecithin: a double-blind trial. $B M 7$ 1994;308:879-83.

6 Eagger SA, Levy R, Sohakian BJ. Tacrine in Alzheimer's disease. Lancet 1991;337:989-92.

7 Davis KL, Thal LJ, Gamzu ER, Davis CS, Woolson RF, Gracon SI, et al. A double-blind, placebocontrolled multi-centre study of tacrine for Alzheimer's disease. The Tacrine Collaborative Study Group. N Engl F Med 1992;327:1253-9.

8 Farlow M, Gracon SI, Hershey LA, Lewis KW, Sadowsky CH, Dolan- Reno J. A controlled trial of tacrine in Alzheimer's disease. The Tacrine Study Group. ₹AMA 1992;268:2523-9.

9 Eagger S, Levy R. Serum levels of tacrine in relation to clinical response in Alzheimer's disease. International fournal of Geriatric Psychiatry 1992;7:115-9.

10 Burns A, Levy R. Clinical diversity in late onset Alzheimer's disease. Oxford: Oxford University Press, 1992. (Maudsley monograph.)

11 Jorm A. Subtypes of Alzheimer's disease: a conceptual analysis and critical review. Psychol Med 1985;15:543-53.

12 Byrne EJ. Diffuse Lewy body disease: disease, spectrum disorder or variety of Alzheimer's disease. Intermational foumal of Geriatric Psychiatry 1992;7:229-34.

13 McKhann G, Drachman E, Folstein M, Katzman R, Price D, Stadlan EM. Clinical diagnosis of Alzheimer's disease: report of the NINCDS-ADRDA work group under the auspices of the Department of Health and Human Services Task Force on Alzheimer's disease. Neurolog 1984;34:939-44.

14 Perry RH, Irving D, Blessed G, Fairbairn A, Perry EK. Senile dementia of Lewy body type. A clinically and neuropathologically distinct form of Lewy body dementia in the elderly. $\mathcal{I}$ Neurol Sci 1990;95:119-39.

15 O'Brien JT, Syed GMS, Levy R. The effects of tacrine on regional cerebral blood flow in Alzheimer's disease. International Yournal of Geriatric Psychiatry 1992;7:835-8.

16 Maurer K, Dierks T. Functional imaging procedures in dementias: mapping of EEG and evoked potentials. Acta Neurol Scand 1992;139:40-6.

\title{
Psychosexual implications of gynaecological cancer
}

\author{
Talk about it
}

Sexual dysfunction is common among adults with cancer, ${ }^{1}$ and women with gynaecological cancer are no exception. ${ }^{23}$ -Much of this is easily explained, given that most patients with cancer experience anxiety or depression after diagnosis and during treatment. To this may be added other aspects of their condition or treatment that make sex difficult-chronic fatigue, nausea, diarrhoea, altered genital appearance or loss of the vagina, tender scars, pain, malodour, alopecia, nervousness about breakdown of the wound, embarrassment about stomas, or advanced disease. What is less clear is why, after "successful" treatment, some women continue to have sexual difficulties.

Most of the organic causes of this problem relate to treatments that alter the genital area. Radical vulvectomy removes the clitoris (although orgasm may still occur ${ }^{4}$ ), renders the tissues tight and devoid of fat "cushioning," and may result in prolapse of the posterior vaginal wall or vaginal stenosis. Radical hysterectomy shortens the vagina, and pelvic exenteration removes it entirely. Radiotherapy renders the vaginal mucosa dry, easily traumatised, stenosed, and less distensible; to this is added the effect of ovarian failure, which in itself causes substantial sexual dysfunction. ${ }^{5}$ Both surgery and radiotherapy may also damage sacral nerves ${ }^{6}$ and cause neurological changes to fine sensory perception in the tissues of the genital area, thus altering sexual sensation and responsiveness. ${ }^{4}$

What makes the sexual dysfunction so difficult to treat, however, is its psychogenic component. Surgery to the breasts and genitals threatens female identity. The disruption of body image, particularly from the mutilating surgery of radical vulvectomy and exenteration, ${ }^{178}$ results in many women never resuming intercourse. ${ }^{38}$ Women with cervical cancer become infertile and increasingly feel guilty that their disease results from their past sexual behaviour. ${ }^{238}$ Somatisation aggravates their anxiety, as every symptomvaginal bleeding, discharge, pain-is attributed to a recurrence of the cancer; women may fear that the disease can be transmitted to their male sexual partner. ${ }^{38}$

In a study that we recently carried out with colleagues only one in four previously sexually active women had no sexual dysfunction after radical vulvectomy, radical hysterectomy, or exenteration. ${ }^{3}$ In three quarters sexual difficulties persisted for more than six months postoperatively; $15 \%$ never resumed intercourse. Lack of desire was the commonest problem, and the factors that increased the likelihood of sexual dysfunction or failure to resume intercourse were age over 65 , short length of marriage or marital disharmony before the surgery, and radiotherapy (associated with sexual difficulties in $80 \%$ of women under 50). Widows and women not currently in a sexual relationship (particularly young and childless women) were very anxious about or refused to contemplate initiating a future sexual relationship.

Knowledge about such sexual dysfunction permits two treatment strategies. Firstly, in some cases gynaecological cancer can be managed so as to minimise physical mutilation and preserve ovarian function. We do not recommend radiotherapy for women under 50 if radical hysterectomy will produce equally good results; even an intracavitary source without external beam radiotherapy destroys ovarian function. ${ }^{9}$

Women with microinvasive cervical cancer $<3 \mathrm{~mm}$ who wish to conserve their fertility may be safely treated by therapeutic cone biopsy. ${ }^{10}$ Should radiotherapy be necessary for women with cervical cancer they should be instructed to apply oestrogen cream to the vagina during treatment, with rigorous vaginal dilatation and Kegel pelvic floor exercises to promote blood flow to the area. Superficial microinvasive vulval carcinoma may be treated by wide local excision, and even radical vulvectomy may be modified from the classic "butterfly" incision to produce a more aesthetic and comfortable result. In patients who have anterior exenteration the use of part of the ileum and caecum to recreate the bladder and vagina is increasingly successful. ${ }^{11}$

Secondly, dialogue about sexual matters with each follow up visit is essential, although this is rarely initiated by the patient, and often not by her doctor. Sexual counselling is effective in reducing long term morbidity, ${ }^{12}$ even for those who have had exenteration. It needs to begin preoperatively, with the sexual partner present, and involves educating the patient about her anatomy and discussing sexual techniques and alternatives (for example, orogenital sex or mutual masturbation), which may be needed as permanent substitutes 